J. Clin. Chem. Clin. Biochem.

Vol. 27, 1989, pp. 639-642

(C) 1989 Walter de Gruyter \& Co. Berlin - New York

\title{
Analysis of Urinary Stones by Computerized Infrared Spectroscopy ${ }^{1}$ )
}

\author{
By A. Hesse, M. Gergeleit, P. Schüller \\ Experimentelle Urologie, Universität Bonn and \\ K. Möller \\ Institut für Informatik, Universität Bonn, F.R.G.
}

(Received March 4/July 18, 1989)

Summary: The computerized assessment of infrared spectra of urinary stones with existing programmes such as SEARCH (Lehmann, C. A. et al. (1988) Clin. Chim. Acta 173, 107-116), TWIN or CIRCOM (Hesse, A. et al. (1988) Fresenius Z. Anal. Chem. 330, 372-373) has proved to be unreliable when used for routine urinary stone analysis. A more refined method has to be used in place of simple comparison algorithms. STONES is a new programme for computerized analysis of urinary stones developed with the intention of simulating the former non-computerized analysis procedure. STONES is a rule-based system, which interprets the infrared spectra qualitatively by its rules. A quantitative result is obtained by means of library search. Combining these two methods $93 \%$ of the tests were correct with regard to clinical relevance.

\section{Introduction}

Infrared spectroscopy is one of the few methods available which meets the requirements for both sensitivity and specificity in the analysis of urinary stones $(1-4)$.

The results obtained in the quality control of chemical stone analyses using ring surveys are so poor as to be irresponsible, whereas those obtained using X-ray diffraction are mostly very good and comparable with results provided by infrared spectroscopy $(4,5)$.

As the constituents of urinary stones are well known, the computerized assessment of infrared spectra might appear to be a comparatively simple matter. However, over $65 \%$ of all concrements are of mixed composition, with the result that the existing programs such as SEARCH (6), TWIN or CIRCOM (7), with their general rules for automated spectrum assessment, have proved to be very unreliable when used for routine urinary stone analysis.

1) The project was sponsored by the "Ministerium für Wissenschaft und Forschung des Landes Nordrhein-Westfalen" FRG, No. 40202887
Hence a new program - STONES - has been written which has been specially tailored to accommodate urinary stone substances of every known composition.

\section{Material and Methods}

\subsection{Basic principle of the method}

During the development of the program due regard was paid to the normal procedure whereby, for example, a qualitative interpretation of the transmission bands based on personal experience or additional spectrum comparison is followed by the quantitative assessment of the stone composition using reference spectra. With STONES, a qualitative analysis is first made based on expert knowledge, which is followed by a quantitive analysis based on the results of the second stage. This second analysis involves combining through a library containing all the relevant pure substances and mixtures of two and three substances.

\subsection{Technical prerequisites for STONES}

Hardware: Perkin-Elmer Model 598 Infrared Spectrophotometer; Perkin-Elmer Model 7300 Professional Computer, 15 Mbyte Winnchester; 640 Kbyte RAM, Motorola 68000 Microprocessor.

Software: Idris operating system (UNIX $\left.{ }^{\circledR}\right) ;$ programming language $C$, STONES analysis program. 


\subsection{Description of a spectrum}

Each individual spectrum of a urinary stone substance is characterised by the position and intensity of its bands. In addition to this, the program also takes into account characteristic shoulders and the breadth of the bands (figs. 1a, 1b). The relative intensities of the bands are also determined. After arithmetical scaling and smoothing of the spectrum, the bands are classified accordingly. Superposition of the bands leads to the formation of shoulders, which can be mathematically described as saddles, and which are of particular importance for the analysis of mixtures.

The arithmetical values thus obtained are classified according to their significance and compiled into a list in the computer program.

The descriptions are undertaking on the basis of the 9 most important urinary stone substances, and their variability in the possible mixtures. A total of 273 spectra from the library were used for this purpose.
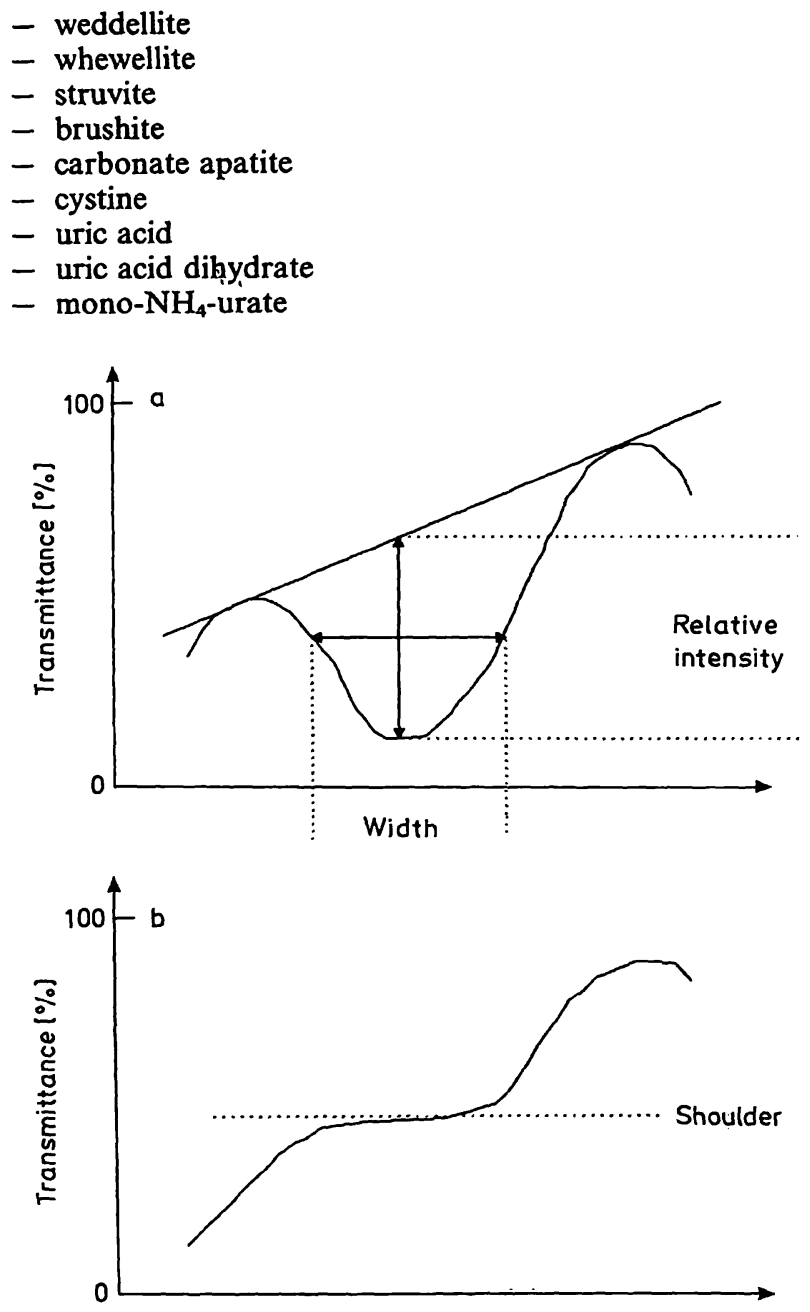

Fig. 1. Diagram showing the determination of (a) the relative intensity and breadth of a band (left); (b) and of a shoulder of the curve (right).

\subsection{Qualitative analysis}

A rule interpreter was specially developed for the analysis of individual substances which enables possible substances to be either excluded or identified.

All these rules have a similar basic structure. Below is an example based on the procedure for obtaining direct proof of the presence of weddellite:
- The band at $1639 \mathrm{~cm}^{-1}$ is checked for presence and characteristics

- wavenumber $<1644>1634 \mathrm{~cm}^{-1}$

- intensity - very strong

- breadth - broad

- The band at $1323 \mathrm{~cm}^{-1}$ is checked for presence and characteristics

- wavenumber $<1330>1320 \mathrm{~cm}^{-1}$

- intensity - very strong if

- breadth - narrow

- Linking with the band at $777 \mathrm{~cm}^{-1}$

- wavenumber $<786>774 \mathrm{~cm}^{-1}$

- intensity - not strong

The meeting of all these conditions will provide qualitative proof of the presence of weddellite.

Rule: the presence of weddellite is proved as the bands at 1640 and 1323 are very strong and that at $777 \mathrm{~cm}^{-1}$ is not strong.

\subsection{Quantitative analysis}

Based on the results of the qualitative analysis a comparison with selected reference spectra from the spectrum library is now performed. Spectra containing elements which had already been excluded in the qualitative analysis are not presented for comparison.

The analysed sample spectrum will now appear on the screen below the spectrum of the quantitative analysis. This enables the analysis to be verified. The result of the analysis will then also be presented on the screen.

For the purposes of documentation, all these data can be printed out, working from the menu.

\section{Results}

\subsection{Presentation of a result}

The result contains data on a maximum of 3 substances. For each substance 3 stages of identification are possible: presence identified - suspected - cannot be excluded. The first of these indicates a positive identification, whereas the next one indicates the high possibility that the substance is present in a mixture with many superimposed bands. The notice „cannot be excluded" means that a substance can be neither identified nor excluded.

Example: spectrum g8n1w1s.sp

Whewellite, presence identified $80 \%$

Struvite, presence identified $10 \%$

Weddellite, presence cannot be excluded $10 \%$

This analysis was correct!

\subsection{Checking the capability of STONES}

A series of tests involving 130 analyses of natural urinary stones was arranged to check the STONES

J. Clin. Chem. Clinn. Biochem. / Vol. 27, 1989 / Nô. 9 
program. When selecting the stones, care was taken to ensure that all the typical classes of substance were represented. Forty three stones consisted of whewellite or weddellite, or of mixtures of the two combined with carbonate apatite. Thirty concrements consisted of struvite/carbonate apatite. Five stones contained brushite. Uric acid was the main constituent in 33 stones, mono- $\mathrm{NH}_{4}$-urate in 18 stones, and cystine in 4 stones. Infrared spectra were prepared from $\mathrm{KBr}$ pellets pressed from powder $(3,8)$.

\subsubsection{Qualitative analysis}

The infrared spectra were examined independently by an expert and by the program. The expert's results were taken as references. The assessment was divided into 4 categories:

\section{I correct in all elements}

II correct in relation to clinical relevance

III false positive or false negative; the amount of the substance identified was either too small or too large

IV false analysis or not assessable.

Of all analyses, 83 (63.8\%) fell into category I and $38(29.2 \%)$ into category II, so that $93 \%$ were clinically relevant (fig. 2). In the majority of the analyses in category II there were problems in differentiating between whewellite and weddellite, or no firm distinction could be made between uric acid and uric acid dihydrate. In the case of 8 analyses $(6.2 \%)$ one substance too many or too few was found. No incorrect treatment would have ensued from the false assessment of these calculi. In one case $(0.8 \%)$ the spectrum could not be assessed using STONES. No misinterpretations of the chief constituents occurred.

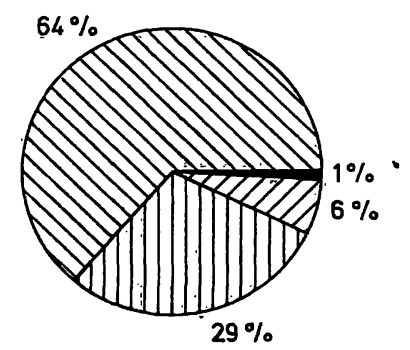

Fig. 2. Diagram showing the assessment of the qualitative analysis using STONES.

$1 \%$ : not evaluable;

6\%: false positive/negative;

$29 \%$ : clinically correct;

$64 \%$ analytically correct.

\subsubsection{Quantitative analysis}

The performance of the quantitative analysis was assessed from the analytical results for mixed stones, i. e. whewellite, weddellite, carbonate apatite and struvite mixed stones. The results are presented in figures 3 to 6 .

When assessing these results, it must be borne in mind that this quantitative assessment is not always easy for the human expert, if no test spectra from finely graded mixtures are available. The mean deviations of 9.7 to $14.7 \%$ are of no clinical significance.

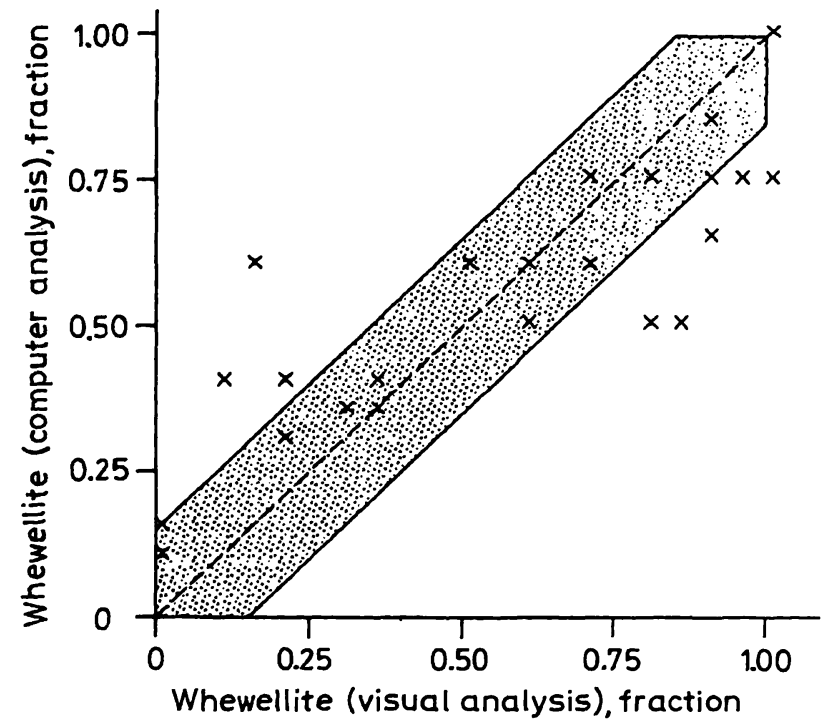

Fig. 3. Comparison of the results of the quantitative analysis of whewellite mixed calculi, fraction by weight $(n=23)$, mean deviation $13.9 \%$. Stippled area corresponds to fractions of \pm 0.15 .

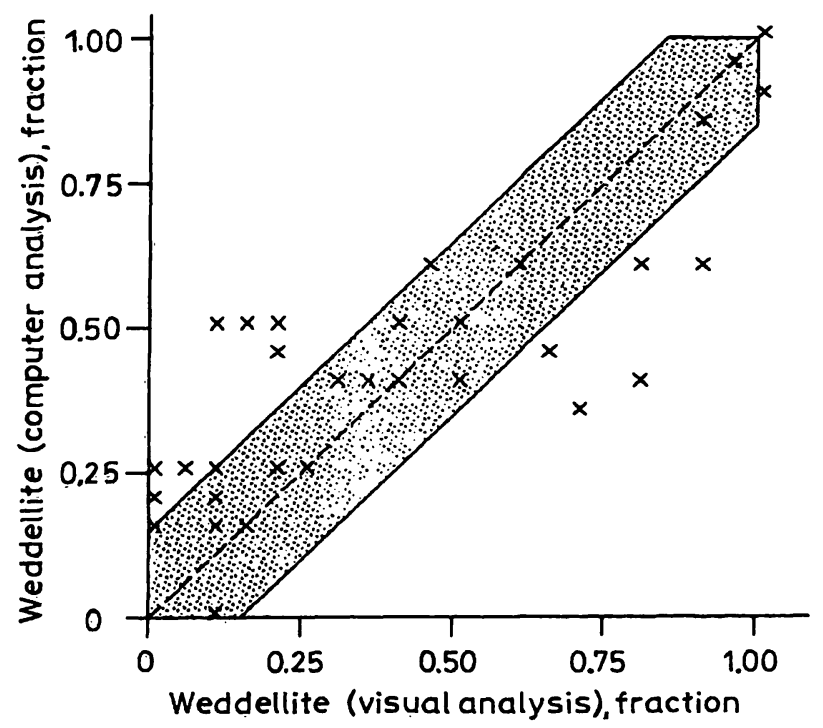

Fig. 4. Comparison of the results of the quantitative analysis of weddellite mixed calculi, fraction by weight $(n=32)$, mean deviation $14.7 \%$. Stippled area corresponds to fractions of \pm 0.15 . 


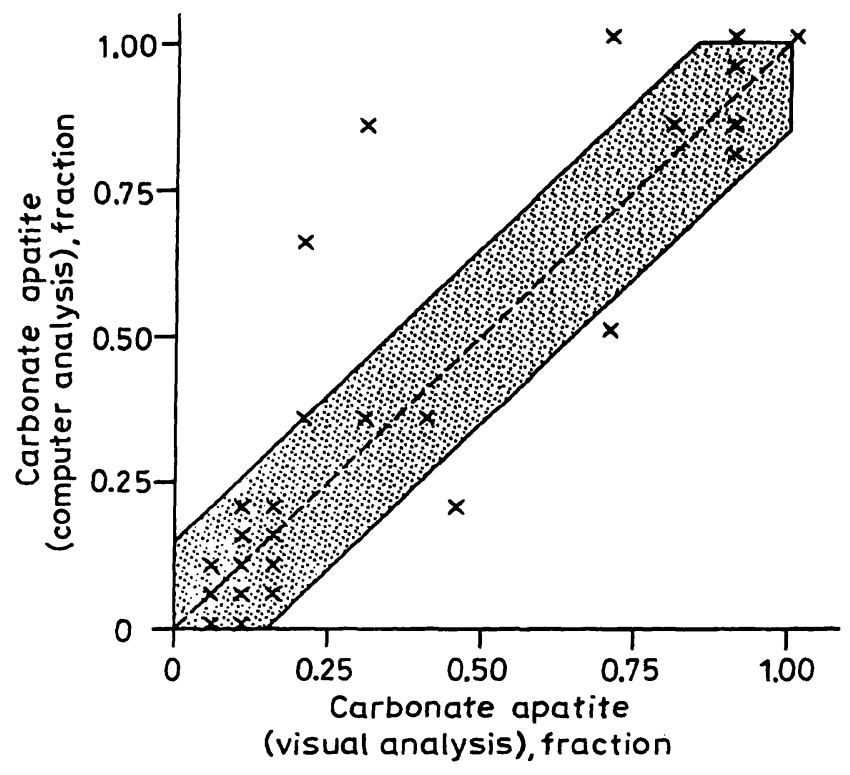

Fig. 5. Comparison of the results of the quantitative analysis of carbonate apatite mixed calculi, fraction by weight $(n=26)$, mean deviation $9.7 \%$. Stippled area corresponds to fractions of \pm 0.15 .

\section{Overall assessment of STONES}

This program was developed to provide a reliable method of characterizing urinary stones using infrared spectroscopy, and thus reduce the degree of expert knowledge required. The present version of STONES is already displaying a surprisingly high degree of reliability in quantitative analysis, and there is still scope for improvement in certain borderline cases. Hence tests on a suitable number of analyses must be continued. The shortcomings in quantitative analysis

\section{References}

1. Daudon, M., Protat, M. F., Reveillaud, R. J. \& JaeschkeBoyer, H. (1983) Infrared spectrometry and raman microprobe in the analysis of urinary calculi. Kidney Internat. 23, $842-850$.

2. Gault, M. H., Ahmed, M., Kalra, J., Senciall, I., Cohen, W. \& Churchill, D. (1980) Comparison of infrared and wet chemical analysis of urinary tract calculi. Clin. Chim. Acta 104, 349-359.

3. Hesse, A. \& Molt, K. (1982) Technik der infrarotspektroskopischen Harnsteinanalyse. J. Clin. Chem. Clin. Biochem. 20, $861-873$.

4. Röhle, G., Voigt, U., Hesse, A. \& Breuer, H. (1982) Ergebnisse aus Ringversuchen für Harnsteinanalysen. J. Clin. Chem. Clin. Biochem. 20, 851-859.

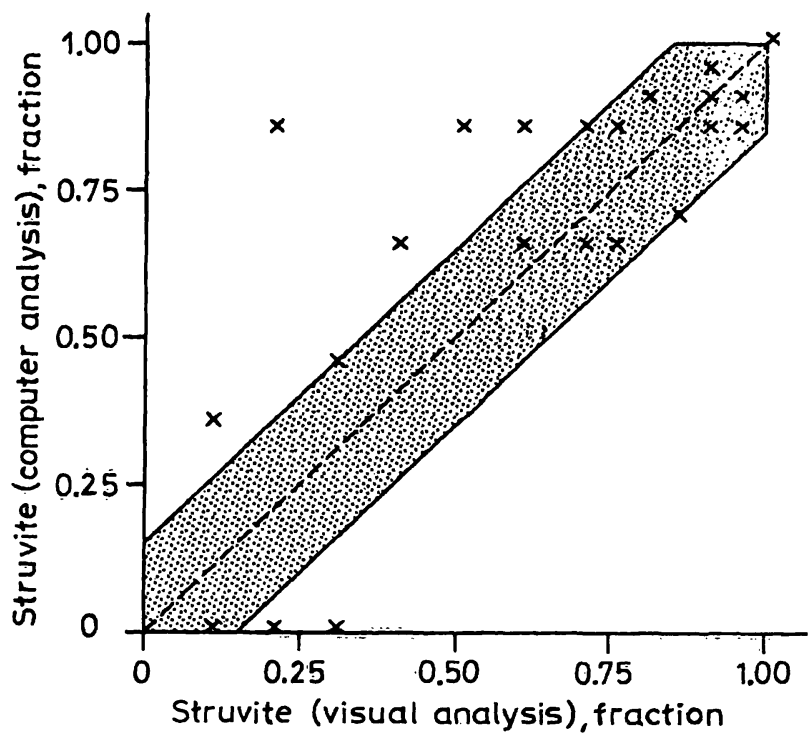

Fig. 6. Comparison of the results of the quantitative analysis of struvite mixed calculi, fraction by weight $(n=22)$, mean deviation $12.2 \%$. manifested by the program must also be checked, and hopefully diminished, by comparing this method with another objective method (X-ray diffraction). In any case, the aberrations found to date have not had any true clinical rèlevance.

From the information contained in the literature (6) and from our own experience with other programs we are confident that STONES will soon provide a program acceptable for all routine urinary stone anal= ysis purposes.

5. Rebentisch, G. \& Berg, W. (1984) International ring test to check the quality of urolith analysis. Eur. Urol. 10, 196201.

6. Lehmann, C. A., McClure, G. L. \& Smolens, I. (1988) Identification of renal calculi by computerised infrared spectroscopy. Clin. Chim. Acta 173, 107-116.

7. Hesse, A., Sanders, G., Döring, R. \& Oelichmann, J. (1988) Infrarotspektroskopische Harnsteinanalyse: automatisierte Spektrenauswertung mit Hilfe der Faktorenanalyse. Fresenius Z. Anal. Chem. 330, 372-373.

8. Hesse, A. \& Sanders, G. (1988) Infrarotspektren-Atlas zur Harnsteinanalyse. Atlas of Infrared Spectra for the Analysis of Urinary Concrements. Georg Thieme Stuttgart New York.

Prof. Dr. A. Hesse

Experimentelle Urologie

Urologische Universitätsklinik

Sigmund-Freud-Straße 25

D-5300 Bonn 1 